was, apparently, in good health. When sitting down to dinner in the evening she complained of a tight feeling across the forehead and neck; she immediately vomited and lost consciousness within a fow minutes. She did not recover consciousness and died four hours from the onset. In this case also the frothy fluid did not appear in the mouth until one hour after the beginning of the attack, the lungs became gradually waterlogged, the lower lung showing more numerous râles than the upper when the patient was lying on her side. The blood pressure was slightly raised, being $140 \mathrm{~mm}$. systolic, and the heart was definitely hypertrophied. In this case also a specimen of urine was not available, as the patient had passed it involuntarily at the onset of the attack. When her relatives arrived it was ascertained that she had had scarlet fever three years ago and had been subsequently put on a diet from which meat was excluded owing to high blood pressure. The fluid continued to well up into the mouth and nose as long as respiratory movements were made. Morphine and atropine injections did not benefit her.

CAse 3 was a woman aged 62 , who was suddenly taken ill during the night after a journey to London. She became very dyspnœic, cold and cyanosed, with a feeble and rapid pulse, and the lungs were full of bubbling râles. In this case consciousness was not lost and the pulmonary œdema was not so severe, as frothy fluid did not well up into the mouth. Injection of morphine gr. $\frac{1}{6}$ and atropine gr. 1/100 was followed by a wonderful result, the dyspnœea and bubbling in the lungs being immediately relieved. The next morning the lungs were clear, except for some œdema of the left lower lobe. Definite signs of cardiovascular degeneration were present, the heart being enlarged, the arteries thickened, the systolic blood pressure $170 \mathrm{~mm}$., and the urine contained much albumin. The patient gave a history of an attack of acute nephritis following a chill 15 years previously, and had suffered from a septic throat five years before this. No difficulty in breathing had been noted until the last nine months, during which the patient had had several minor attacks of nocturnal dyspnœa.

The subsequent convalescence was notable for the rapidity with which the albuminuria vanished. A small pleural effusion developed on the left side, which was absorbed without aspiration. The patient proved to be an example of the recurrent or paroxysmal type of acute pulmonary cdema, which has been described by several authors. Thus attacks have been known to extend over a period of 10 years, and as many as 72 seizures during a space of two years have been recorded. It has also been noted that this recurrent variety is nearly always associated with cardiovascular disease or with nephritis.

Almost a year later this patient had a second attack, the lungs becoming flooded with fluid and the pulse-rate rising to 132. The attack again occurred at about 2 A.M., and was aborted by an injection of morphine gr. $\frac{1}{4}$ and atropine gr. 1/100. The urine was once more loaded with albumin, whereas only a week previously it had been examined and found free from protein. Vomiting occurred several times during the following morning, and a small pleural effusion again appeared on the left side with some residual œdema at the right base and a little dry pleurisy.

A week later the patient had a third attack which was less severe than the previous ones, and again responded well to morphine and atropine injections.

\section{Diagnosis and Treatment.}

At the onset of the attack the question of a cerebral vascular lesion or coma from some other cause naturally arises. As soon, however, as the codema of the lungs appears and the fluid wells up into the mouth there is little doubt as to the correct diagnosis. In less severe cases in which there is not such a copious exudation the presence of bubbling râles in the lungs may suggest the diagnosis of acute suffocative catarrh as opposed to acute suffocative pulmonary œdema. The former is, however, an infective process, known also as acute purulent bronchitis, and associated with purulent expectoration and pyrexia.

There is no doubt that the most efficacious treatment consists in the immediate injection of morphine in doses up to gr. $\frac{1}{3}$. This is strongly in favour of the disease having a cardiac origin. Atropine gr. 1/100 is usually given in conjunction with the morphine, although its use is probably not essential. In cases which are likely to recover the injection usually affords very rapid relief. Other methods which are recommended are venesection, inhalation of amyl nitrite, and dry cupping. It is very doubtful, however, if any form of treatment will succeed if an injection of morphine and atropine fail.

\section{ABDOMINAL TUBERCLLOSIS IN CHILDREN.*}

\author{
BY \\ C. E. SUNDELL, M.D. LoND.,
}

CONSULTING PHYSICIAN, EVELINA HOSPITAL FOR CHILDREN, ETC.

INFECTION of the abdominal cavity and its contents by tubercle is apt to assume forms of striking severity in the child in contrast to their comparative rarity in the adult. In the lattero abdominal tuberculosis in a severe form is usually a late event in the course of tuberculosis elsewhere in the child it is far more often the major or only disability. Not only is this the case but it is also true that in the child who manifests signs of tuberculosis elsewhere the oldest lesion is to be found in the majority of cases in the abdomen. Experience in the post-mortem room shows clearly that when tuberculous bronchial glands or tuberculous invasion of the lung are found in a child some involvement of the abdominal contents is almost invariably present. To find this it may be necessary to examine closely any. enlarged glands in the mesentery and to explore the thoracic duct, in such glands or in the lumen of this duct are often to be found evidences of tubercle which remain unrevealed to a hurried and casual inspection.

\section{The Route of Infection.}

Whatever views may be held as to the route of tuberculous infection as met with in the adult, there can be no question that in the child the alimentary tract is the common portal of entry. Apart altogether from the danger of tubercle-infected milk (a danger which is yearly becoming smaller owing to quickening of the health-conscience of the community), the floor-loving and toy-sucking propensities of the young child expose it to the risk of swallowing tubercle-infected dust at all hours of the day.

* A Lecture delivered at the North-East London Post-Graduate College on July 23rd, 1926. 
From the point of view of treatment it is of little or no importance to differentiate between human and bovine strains of tubercle bacilli when we are faced with a child whose abdomen has become the seat of a tuberculous lesion. Whether his condition is due to swallowing milk from a tuberculous udder or to sucking a toy which bears upon its dusty surface dried human tubercle bacilli, the course of the disease and the treatment necessary remain the same.

\section{Differing Characteristics of the Disease.}

Into the classical divisions of abdominal tubercle it is not my purpose to enter; in practice the distinction between the ascitic, caseous, and nodular forms is far less clear than perusal of textbooks would suggest. Usually the abdomen presents characteristics of all forms-one may dominate the picture but the others are not absent, and they are all to be regarded as differing responses to the same infection. At the same time cases are met with in which one form is peculiarly intense. As an example of this, the rare form of acute ascites may be mentioned. The child affected with tubercle may react so violently to the invasion as to produce a picture strongly suggestive of the acute abdomen with high fever, rapid pulse, rapid distension of the abdomen with fluid, and a boardlike resistance of the abdominal walls. When such an abdomen is opened nothing is found except a varying number of miliary tubercles upon the peritoneum, a large quantity of clear or opalescent fluid, and some matting of intestinal folds. These cases are so uncommon that laparotomy remains the wisest course, although if the condition could be diagnosed without inspection of the peritoneum, such a step would be unnecessary.

As a contrast to this rare form of disease, a far more common type may be mentioned-i.e., localised glandular infection. This leads to symptoms which are essentially chronic; very often they lead to the diagnosis of chronic appendicitis-a label which is suggested by the complaints of recurring pain in the abdomen, localised vaguely or clearly according to the mental development of the child to the right iliac fossa, by irregularity of bowel function, signs of general ill-health, and occasional febrile attacks with or without vomiting ; on examination indefinite resistance in the appendix region may serve to emphasise the suggestion that the appendix is at fault. Such reasoning is probably correct in the case of an adult; in the case of a child it is far more likely to be wrong. Operation will reveal one or a few caseous or calcareous glands in the region of the ileo-cæcal valve with local redness of the peritoneum investing them; the appendix will probably be found to be above suspicion.

This simulation of chronic appendicitis by tuberculous adenitis deserves to be more widely appreciated. In case of doubt it is well worth while having $X$ ray plates taken in two planes; the antero-posterior view will reveal the presence of a calcareous gland and the lateral view may show that it is lying among the contents of the abdomen rather than upon its wall. Excision of such glands is indicated when the symptoms to which they give rise are severe; in many cases they become firmly encapsuled and cease to give rise to trouble as the child grows older and reliance can with safety be placed upon general measures.

"Consumptive Bowels."-A diagnosis much in favour among mothers of young out-patients very rarely denotes tuberculosis. Far more often the symptoms are due to flatulent dyspepsia, excess of carbohydrates in the food, and rickets. A swollen belly in a child is not due to tubercle unless it contains evidence of fluid, matting of soft contents or some kind of a lump.

Coeliac disease may ape very closely the signs and symptoms of abdominal tuberculosis ; it is suggested by the bulk of the motion and the practical impossibility of digestion of fat in any form, it is just as common in the child of the well-to-do parents who exercise scrupulous hygienic care as in the relatively neglected child of the hospital out-patients' department. The bulk and pallor of the motions in these children usually first arouse a suspicion which is strengthened by the stunting of growth (amounting in some cases to infantilism) and the signs of general ill-health. There is nothing definitely characteristic about the motions of the tuberculous child which can be noted as a diagnostic feature; their two most striking features are their irregularity and their foulness ; blood and mucus are rarely seen unless there is ulceration of the lower bowel-an event which occurs long after the diagnosis has been established.

\section{Treatment.}

It is essential to recognise that abdominal tuberculosis is slow in healing; 12 months is the minimum period necessary to establish a cure. Tuberculin is rapidly losing favour ; it is becoming realised that it is a weapon of some danger and that the cases that do well on tuberculin will do well without it. Putrefaction of bowel contents is to be prevented by reducing meat and eggs, by administration of charcoal and an occasional dose of a mercurial aperient. Inunctions of mercury have a real value in cases associated with marked ascites; laparotomy and drainage of fluid are occasionally advisable.

With these exceptions reliance is to be placed rather upon general measures to increase the natural resistive and immunising powers of the body.

Rest is of prime importance ; it must be made clear from the outset that the child will have to remain in bed or on a wheeled couch for at least six months; nothing can take the place of this, and if necessary the whole routine of the household must be made subservient to this rule. At the end of this period, if the temperature has remained normal for six weeks, gradual relaxation of the law of rest can be allowed. 
Sunshine is the second great weapon, real if possible, artificial if this cannot be obtained. In the early stages of treatment great care is necessary to avoid an overdose ; this care cannot be relaxed until pigmentation has developed strongly. It is well to proceed by gradual stages-shade-light, sky-light, sunlight, and to expose small areas of the body at first and for ten minutes at a time only. It is not necessary to concentrate the rays upon the abdomen; sunlight produces general effects upon the body which are of greater importance than its local effect upon the seat of disease.

In the cure of abdominal tuberculosis in children we can do much by the removal of hindrances to recovery such as intestinal putrefaction and absorption of poisons, but good results are to be expected only through the natural reparative properties of the child's tissues aided by complete rest and careful sunning.

\section{ERRORS OF REFRACTION, WITH SPECIAL REFERENCE TO SQUINT.*}

BY

\author{
A. F. M a C C A L L A N, C.B.E., M.D. Camb., \\ F.R.C.S. ENG.,
}

ASSISTANT OPHTHAJMIC SURGEON, WESTMINSTER HOSPITAL; ASSISTANT SIRAEON, ROYAL, FYE HOSPITAI.

THE remarks which I am about to make on the subject of errors of refraction are directed to those who are already in general practice, and I shall confine myself as much as possible to points of which students text-books say little. It will be convenient if the matter is considered according to the various periods of life, taking first infancy and then the succeeding decades.

\section{INFANCY.}

Most children at birth are hypermetropic, that is to say, the eyeball is small and rays of light entering the cornea, instead of being brought to a focus on the retina, are focused behind the retina, and the image formed is indistinct. By the fourth or fifth month development of the eye has progressed, the child begins to fix objects for more than a few seconds, the eyes are often parallel, and binocular vision is being acquired. At this time there may be occasional squint in a lateral plane, but not in a vertical plane. This may be neglected unless it is observed to be a constant squint, or at any rate of frequent occurrence. In such a case it is important that an accurate estimation of the refractive error should be made by retinoscopy, and that if there is hypermetropia a suitable correction should be ordered. If there is hypermetropic astigmatism

* A Clinical Lecture, with exhibition of cases, delivered before the Fellowship of Medicine and Post-Graduate Medical Association on July 8th, 1926 . found, the astigmatism should certainly be corrected ; but it is of the first importance that the examination should be carried out by one who is both expert and in the habit of prescribing glasses. Glasses may be.worn without the slightest difficulty in many children of 5 or 6 months of age, and if there is difficulty it must be overcome by patience and subtlety on the part of the mother and the nurse.

\section{Chuldhood.}

In the absence of any squint, errors of refraction are not usually manifest until the child is 5 or 6 years old. Also a squint may not develop until that age or frequently even later. When the child begins to play with small toys it may be noted, in cases of myopia and hypermetropia, that he brings the object within five or six inches of the eyes. This should make evident the necessity for ophthalmic examination. Again, the occurrence of redness of the lid margins, or blepharitis, is evidence to the same effect.

If hypermetropia is present in childhood there is a tendency to convergent squint, for the child, in order to focus properly distant as well as near objects, must exert accommodation to allow the lens to become more convex, and bring the parallel rays of light to a focus on the retina; it will be remembered that in the normal emmetropic eye parallel rays of light, in the absence of accommodative effort, are brought to a focus on the retina. With efforts of accommodation there is always a corresponding amount of convergence, and if ance abnormal amount of accommodation is used, an abnormal tendency to convergence of the two eyes is produced, and if the desire for fusion of the images in the brain is not very strong, an actual convergence or squint is produced. The earlier the abnormal accommodative efforts are made, the more tendency there is to the development of squint, as at an early age fusion of the images from the two eyes has not been learnt.

Divergent squint is usually associated with myopia. It is probably generally developed when the child begins to go to school. He brings his book closer to the eyes than is convenient for his converging power in order to obtain clearer vision ; it rests him to close one eye which diverges.

The disfigurement caused by a squint is considerable, but far more important is the great deterioration of vision which may occur in the squinting eye. The disfigurement may be diminished or cured in some cases by wearing the proper glasses, with or without operation; but the deterioration of vision if it once occurs is often permanent, unless special measures to prevent this are taken. This condition is known as amblyopia. In order to prevent amblyopia, we may entirely occlude the good eye, so as to make the patient use the squinting eye, or we may be less drastic and diminish the visual acuity of the good eye by the daily instillation of atropine, which fixes the eye in adaptation for distant vision. 